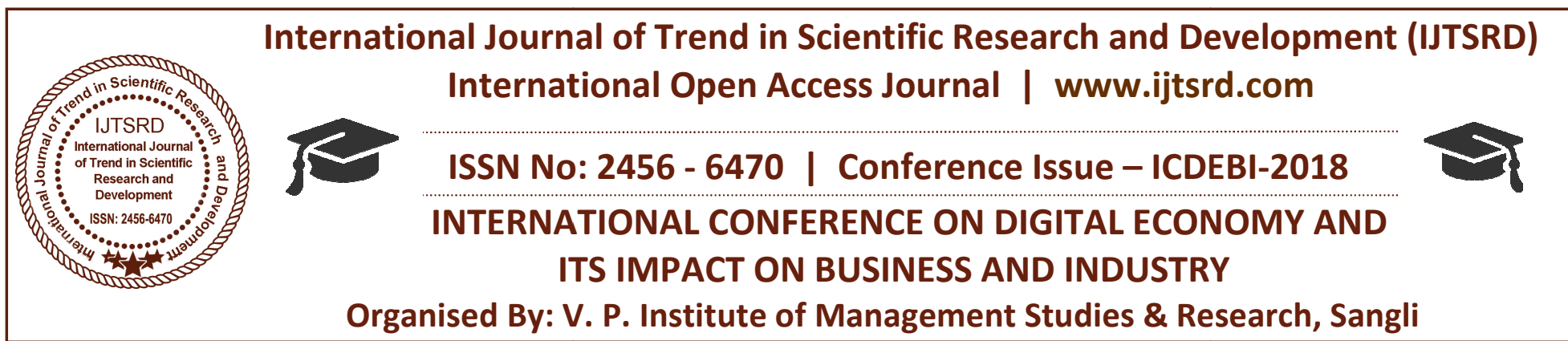

\title{
Opportunities \& Challenges - Digital India
}

\author{
Sunayana Jotiram Jadhav \\ Assistant Professor, S. P. K. Mahavidyalaya, Sawantwadi, \\ Sindhudurg, Maharashtra, India
}

\begin{abstract}
Digital India is the beginning of digital rebellion. It is a vision which is created by the Government of India to make sure that government services are made available to citizens electronically, even in remote areas, by improving online infrastructure and by increasing Internet connectivity. The programme has one mission and one intention that are to take nation forward digitally and economically. The proposal will enable people to get engaged in the innovation process which is needed by the economy to move forward. But to implement this is a great challenge. There are many roadblocks in the way of its successful implementation like digital illiteracy, poor infrastructure, low internet speed, lack of harmonization among various departments, issue pertaining to taxation etc. These challenges need to be addressed in order to realize the full potential of this programme. It requires a lot of pains and dedication from all departments of government as well as private sector. If implemented properly, it will open various new opportunities for the citizens of the country.
\end{abstract}

KEYWORD: Digital, Infrastructure, Opportunities, Revolution, Roadblocks

\section{INTRODUCTION}

The Digital India programme is a flagship programme of the Government of India with a vision to renovate India into a digitally empower society and knowledge economy. Digitalization is one of the most elemental periods of transformation we have ever witnessed. Digital India was a flagship programme launched by the Prime Minister of India Narendra Modi on 1 July 2015 - with an objective of connecting rural areas with high-speed internet networks and improving digital literacy. The vision of this programme is to transform India into a digitally empowered society and knowledge economy. It is one of the major step by government of India to motivate the citizen of the country and connect Indian economy to knowledge savvy world.

\section{RESEARCH METHODOLOGY :}

The paper is based on the secondary data and the information is retrieved from the internet via journals, research papers and expert opinions on the same subject matter.

\section{OBJECTIVE OF THE PAPER:}

1. To study the concept of digital India .

2. To find out the importance of this programme.

3. To find out the challenges faced in implementation of this programme.

4. To find out practical solutions and innovative ideas to accomplish the vision of a digital India-a reality.

DIGITAL INDIA 'Digital India' is a central programme to make India ready for knowledgebased future Vision Areas of Digital India The Digital India programme is centered on three key vision areas:

\section{BENEFITS OF DIGITAL INDIA PROGRAMME}

1. The digital India task would make all the government services available to people of country through common service delivery outlets. 
2. There would be more clearness as all the data would be made online and would be accessible to citizens of the country.

3. E-Governance will help in reducing corruption and getting things done quickly.

4. Digital locker facility will help citizen to digitally store their important documents like Pan Card, passport, mark sheets etc.

5. It will help in decreasing documentation and reducing paper work.

6. Digital India mission is away for cashless transactions.

7. It can help small businesses. People can use online utensils to expand their business.

8. It can play a key role in GDP growth.

\section{PILLARS OF DIGITAL INDIA}

Under Digital India programme, key initiatives are in progress, which are as follows

1. Broadband Highways The aim is to cover 250000 village Panchayats under National Optical Fibre Network (NOFN) by December 2016. Nationwide internet infrastructure (NII) would incorporate the network and cloud infrastructure in the country to give high speed connectivity and cloud stage to various government departments up to the panchayat level.

2. Universal Access to Mobile Connectivity The plan is to increase network dispersion and to provide mobile connectivity to 44000 villages by 2018 with investment of RS 16000.

3. Public Internet Access Programme One Common Service Centre(CSC) would be provided to each gram panchayat and 150,000 Post Offices are proposed to be converted into multi service centers.

4. E-Governance IT would be used to make the delivery of government services more successfully. There would be incorporation of services and platform-UIDAI, Payment Gateway, Mobile Seva platform, Public redressal etc., through IT. All information would be available in electronic form.

5. e-Kranti The plan is electronic deliverance of services to people be it education, health, financial enclosure or justice.

6. Information for AllMyGov.in is a website launched by the government to make easy a 2-way communication between citizens and the government. It is a medium to exchange thoughts or suggestion with government. The citizen would have open right of entry to information throughout open data platform.
7. IT for Jobs The aim is to train 10 million people in towns and villages for IT sector jobs in five years. It also aims to provide education to three lakh service delivery agents as part of skill development to run possible businesses delivering IT services. It also focuses on training of five lakh Rural Workforce on Telecom and Telecom connected services and setting up of BPOs in each North-eastern state.

\section{OPPORTUNITIES}

1. The Digital India programme, India may have an opportunity to encourage and change the world yet again.

2. Positive citizen perception about right of entry to government throughout both conservative and digital channels tender an outstanding and distinguish starting point for governments.

3. Even though clarity seem to be on the agenda of most governments, results are scatter and do not reveal a consistent implementation of this principle.

4. In a recent survey -56 percent of respondents think that digitization of government will generate a service gap for those without Internet access or for citizens who have not yet embrace digital communications.

\section{CHALLENGES}

Few of the challenges are-

1. High level of digital illiteracy:

Cities have adopt digitalization but restricted to certain extent. Full fledged digitalization is cashless transaction on daily basis, use of internet services to get government certificates. These require administration change, Taxation changes and change in public way of thinking. So its team works which include citizen's accountability and bear to the new system. There continues to be a general not have of awareness in Public Service Departments of how digital technology changes public service design to deliver agile, easy-to-use, consumerized services at lesser cost and in a way, that emulate our daily experience in the private sector.

\section{Connectivity to remote areas:}

It is a huge task to have connectivity with each and every village, town and city. The difficulty of connectivity is a complex issue as every state has different laws pertaining to its implementation. Also it is challenging for the central authorities to make a database where such huge information can be stored. 


\section{Compatibility with center state databases:}

Every state has different internet protocols because every state is diversified. Diversified not only in the sense of religion but also in language. Therefore software compatibility with the center is a critical subject. Information shall be saved cautiously.

\section{Cyber Crime:}

There is cyber risk all over the world and digital India will not be any exemption. Hence we have to a strong anti cyber crime team which maintain the database and protect it around the clock.

\section{Inter Departmental Co ordination:}

Inside the government there are a variety of departments which should be integrated. Integration has technical as well as corporate problem. Corporate in the sense self ego of the officers and staff of our government services are obstacle in the change. Also the middle man strategy will be eliminating completely because of digital India, hence there will be imminent resistance from the working staff.

\section{Finance:}

Though there are resources with India but there is an enormous capital cost which is to be invested and the fruits of the investment will be expected after few years.

7. Net neutrality:

The problem is still on the table and we are blindly following the digital India. Net neutrality is having to and we should make confident that digital India exclusive of net neutrality would be a great blow to entrepreneurs and citizens of India.

8. Changing the mindset:

This point will come into picture when you have allocated the necessary resources and material but when it comes to implementing them, most of them will be uncertain to change. People are familiar with years of same of practice that they are not prepared to change.

9. Exchange of information:

The information stored should also be used by other government offices. For example police, surveillance and other security issues can be easily set on with digital India but its co ordination is a massive task. It is not only a technological difficulty but also deals with the question of privacy and safety.

\section{SUGGESTIONS}

Few of the suggestions are -

1. Digital literacy is first step in empowering citizens. People should be familiar with how to protect their online data.

2. Digital divide needs to be addressed.

3. PPP models must be explored for sustainable growth of digital communications.

4. Private sector should be encouraged for development of last mile infrastructure in rural and remote areas. To encourage private sector, there must be favorable taxation policies, quicker clearance of projects.

5. To improve skill in cyber security, we need to introduce cyber security course at graduate level and support international certification bodies to introduce various skill based cyber security courses.

6. There is need for successful participation of various departments and demanding commitment and hard work. A variety of policies in different areas should support this objective.

7. For successful implementation, there must be amendments in a variety of legislations that have for long hindered the growth of technology in India.

\section{SOCIAL IMPACT \& GOVERNANCE IMPACT}

Assessing the impact of digitization on societies is complex because there are no universal metrics that act as a barometer of societal development. Studies often tend to look at the level of inequality in a society but in emerging economies that are in the process of uplifting millions from poverty, a complex relationship between economic escalation and dissimilarity remains. Therefore we analyzed societal impact on two levels: the level of quality of life in a society and the equality of access to basic services that a society requires. However, the analysis reveals that in countries with lower levels of economic development, the impact of digitization is not as marked. The difference appears to be that in fewer developed economies, factors beyond digitization are more significant to quality of life: of primary importance are food; then housing, clothing, water, and energy; followed by health; and finally transportation and communication. As a result, it would appear that, as expected, digitization has an impact on quality of life only when the population has fulfilled its basic needs. 
The final area in which we analyzed the impact of digitization was government effectiveness. As for the analysis reviewed above, we relied on three metrics: the transparency of governmental activities, the delivery of e-government services, and the provisioning of public education a key government service. Our correlational analysis demonstrates that greater digitization enables a society to be more transparent, increasing public contribution and the government's capability to distribute information in an accessible manner. Digital technology gives the population more insight into government policies and function an insight that might, in turn, lead to more energetic political participation and support the development of human rights. Additionally, as expected, e-government services are more useful in a digitized environment. Current research indicates that causality in this case acts both ways. Higher digitization contributes to more efficient delivery of e-government services, while better e-government services stimulate an increase in digitization. Finally, digitization supports better delivery of basic government services, such as public education. In general, our investigation indicates that digitization clearly has a positive impact on economic advancement, societal well-being, and government effectiveness, even though this impact varies according to a country's level of digitization. Digitization has an increasing impact on the economy and quality of life as countries advance through the stages of digitization, and more impact on access to basic services and education in countries that are just beginning their journey.

\section{CONCLUSION}

The digital economy is the new productivity platform that some experts regard as the third industrial revolution. This is also known as 'The Internet Economy' or Internet of Everything (IoE) and expected to generate new market growth opportunities, jobs and become the biggest business chance of mankind in the next 30 to 40 years. The momentum that 'Digital India' has given to our technological progress is noteworthy indeed. The vision of digital India is impressive. It is a enormous step towards building a truly empowered nation. If successful, it transforms citizen access to multimedia information, content and services. However the objective is still far away since most of the nine pillars of digital India mission are facing serious challenges in implementation. It is imperative that focused constant attention must be given to each and every pillar so that this programme does not end up in failure. In fact we all should be mentally prepared for the change and be ready to face the challenges in implementing this policy, only then it would be possible to make this vision a reality. We all support Digital India but we should be aware of the dangers and setbacks, so that we can prepare ourselves for the forthcoming challenge. We should be mentally prepared for the changes and challenges in implementing the policy, only then it would be possible to change it to reality.

\section{REFERENCES:}

1. http://iec.edu.in/blog/digital-india-opportunitieschallenges/

2. http://www.enterpriseitworld.com/index.php/digit al-india-challenges-opportunities/

3. https://www.bbc.com/news/world-asia-india33340425

4. https://en.wikipedia.org/wiki/Digital_India

5. International Journal of Innovative Research in Advanced Engineering (IJIRAE)

ISSN: 2349-2763 Issue 12, Volume 3 (December 2016)

6. www.ijirae.com 